\title{
A PERMANÊNCIA DE DESAFIOS DA GESTÃO URBANA
}

\section{THE REMAINING CHALLENGES OF URBAN MANAGEMENT}

\author{
Gisela Cunha Viana Leonelli 1 \\ Universidade Estadual de Campinas, \\ Faculdade de Engenharia Civil, Arquitetura \\ e Urbanismo, \\ Campinas - SP \\ Editor Convidado \\ gisela@ fec.unicamp.br \\ Leandro Silva Medrano ${ }^{2}$ \\ Universidade de São Paulo, \\ Faculdade de Arquitetura e Urbanismo, \\ São Paulo - SP \\ Editor Chefe \\ leandro.medrano@gmail.com
}

\section{Editorial}

Após quinze anos de aprovação do Estatuto da Cidade (Lei no 10.257/200), a pesquisa científica das áreas de arquitetura e urbanismo e de planejamento urbano e demografia tem apresentado resultados que apontam desafios para a implementação da Reforma Urbana no Brasil (ROLNIK, 2006, 2010), mas também reflexões sobre temas permanentes das cidades brasileiras, como zoneamento, habitação de interesse social e patrimônio histórico-arquitetônico. Tais pesquisas relatam o descompasso entre a evolução dos conceitos urbanos e dos mecanismos de gestão, e a permanência de uma estrutura social patrimonialista que dificulta grande parte das mudanças almejadas (ARRETCHE, 2004; MARICATO, 2011).

Nos primeiros anos após a aprovação da Lei Federal de Desenvolvimento Urbano, o foco das discussões se concentrou na elaboração dos planos diretores e seus instrumentos urbanísticos, promovidos pela intensa Campanha Nacional de Planos Diretores Municipais (BUENO; CYMBALISTA, 2007; SANTOS JR.; MONTANDON, 2011).

Atualmente, a reflexão sobre a gestão urbana no Brasil tem apresentado uma abordagem mais abrangente, para além do plano diretor, trazendo um olhar sobre como os outros instrumentos de planejamento urbano estão sendo implementados, sua relação com as diretrizes do Estatuto da Cidade e consequências para cidades. O território urbanizado passa a incorporar novas estratégias de intervenção e transformação, sendo que muitas delas procuram legitimar-se como alternativa aos modelos generalistas de planificação ou gestão da complexa estrutura fundiária nacional - as cidades passam a ser vistas como fundamento de uma almejada reforma social, e não apenas como o resultado de ações políticas ou institucionais. Trata-se de um processo histórico que ultrapassa as discussões locais e espraia-se por todo o planeta, no qual reivindicam-se outras relações entre o Estado a as questões urbanas (LEFEBVRE, 2009), sobretudo no que diz respeito ao entendimento da cidade como um bem comum (um common) (HARVEY, 2012). Neste contexto, que esta edição sobre planejamento urbano, que a Revista PARC está inserida.

A Revista PARC v.6 n.3 inicia com o artigo de Kazuo Nakano e Sully Alonso Guatella - do Centro Universitário FIAM- FAAM - "A forma urbana a partir de planos diretores e leis de zoneamento do município de São Paulo" que 
apresenta um histórico sobre o deslocamento existente na produção das leis de regulação e controle de parcelamento, uso e ocupação do solo com a forma urbana. Nakano e Guatella remetem às origens do zoneamento convencional e, tendo como exemplo as leis urbanísticas de São Paulo, exemplificam a prática do controle do solo regulador desconectado com a preocupação do desenho urbano. Finalizam com a expectativa do novo plano diretor de São Paulo que tenta resgatar a formulação de um zoneamento que intencionalmente desenhe a cidade e propicie maior qualidade urbana.

O tema da segregação socioespacial na produção da habitação de interesse social é tratado em dois artigos. No primeiro, nomeado "Questões de localização e conectividade na avaliação de qualidade urbana em empreendimentos de interesse social em Indaiatuba" Eloisa Dezen-Kempter, Juliana Camargo Anhaia e Luan de Oliveira Terra - da Universidade Estadual de Campinas - aplicam APO (Avaliação Pós-Ocupação) em três empreendimentos habitacionais destinados à baixa renda na cidade do interior paulista, produzidos em diferentes políticas habitacionais. Os autores relacionam a qualidade da inserção urbana dos empreendimentos habitacionais com as diversas regulações dos planos diretores e leis de zoneamento da cidade estudada.

A inserção urbana da produção da habitação de interesse social também é tematizada no artigo "Territórios Cindidos: o bairro do Bom Retiro e do Conjunto Habitacional Parque do Gato em São Paulo" de Sidney Piochi Bernardini e Renata Venituccio - da Universidade Estadual de Campinas. Metodologicamente, a opção dos autores foi a de analisar a articulação com o território do empreendimento habitacional Parque do Gato localizado no bairro da Barra Funda na capital paulista, por intermédio do resgate dos aspectos históricos, da leitura espacial e análises de padrões morfológicos e de apropriação do espaço.

Os desafios e a complexidade de projetar em centros históricos é o tema do artigo "Intervenções Arquitetônicas no Centro Histórico de Belém: a prática projetual contemporânea" de Marcia T. Figueira Forte e Thais A. B Caminha Sanjade da Universidade Federal do Pará. As autoras alertam para a necessidade de ampliação do debate, da fundamentação teóricaconceitual e do ensino para a prática de projetos nos espaços de memória. Ilustram esta importante discussão de "construir no construído" com a análise de três intervenções no centro histórico de Belém: o Ver- o Peso, Sesc Boulevard e edifício Bechara Mattar.

Finalizando esta edição, Ana Maria Girotti Sperandio et al. - da Universidade Estadual de Campinas - trazem um tema recentemente incluído na discussão da gestão urbana: o planejamento urbano saudável no artigo "Ocupação de vazio urbano como promotor do planejamento para a cidade saudável". Os autores apresentam a experiência de ocupação de vazio urbano por uma horta comunitária na cidade de Conchal - São Paulo, programa pertencente a Rede Nacional de Municípios Saudáveis. A contribuição dada por esta experiência é a implementação da fusão das diretrizes da Política Nacional de Desenvolvimento Urbano (Lei $\mathrm{n}^{\circ}$ 10.257/2001) com a Política Nacional de Promoção da Saúde (Portaria MS/GM no 687/2006) por meio da intersetorialidade da gestão municipal urbana.

\section{Agradecimentos}

Agradecemos aos avaliadores pelo tempo despendido e valiosas considerações tecidas sobre os artigos submetidos.

\section{Referências}

ARRETCHE, M. Federalismo e políticas sociais no Brasil: problemas de coordenação e autonomia. São Paulo em Perspectiva, v. 18, n. 2, p. 17-26, jun. 2004.

BUENO, L.; CYMBAliSTA, R. Planos Diretores Municipais - Novos Conceitos de Planejamento Territorial. 1ed. São Paulo, Editora Anablume, 2007.

HARVEY, D. Rebel Cities: From the Right to the City to the Urban Revolution. 1. ed. [s.1.] Verso, 2012. 
LEFEBVRE, H. State, Space, World: Selected Essays. Traducao Gerald Moore. Minneapolis: Univ of Minnesota Press, 2009.

MARICATO, E. O Impasse da Política Urbana no Brasil. 1. ed. [s.1.] Editora Vozes, 2011.

ROLNIK, R.. A Construção de uma Política Fundiária e de Planejamento Urbano para o País - Avanços e Desafios Políticas Sociais - acompanhamento e análise, Brasília, Rio de Janeiro, n. 12, fev. 2006. p. 199-210. Disponível em: <http://www.ipea.gov.br/portal/index.php?option=com_content\&view=article\&id=5774\&Itemid=9.>. Acesso em: 10 mar. 2016.

ROLNIK, R.. Democracia no fio da navalha: limites e possibilidades para a implementação de uma agenda de Reforma Urbana no Brasil. Revista Brasileira de Estudos Urbanos e Regionais, Recife, v. 11, n. 2, set. 2009. Disponível em: <http://unuhospedagem.com.br/revista/rbeur/index.php/rbeur/article/view/219>. Acesso em: 10 mar. 2016.

SANTOS JR., O. A.; MONTANDON, D. T.. Planos diretores municipais pós Estatuto das Cidades: balanço crítico e perspectivas. 1ed. Rio de Janeiro: Letra Capital, 2011.

\section{${ }^{1}$ Gisela Cunha Viana Leonelli}

Arquiteta e Urbanista. Doutora em Arquitetura e Urbanismo pelo IAU-USP. Professor Doutor II (UNICAMP). Endereço postal: Av. Albert Einstein, 951, Campinas, SP, Brasil, CEP 13.083-852.

\section{${ }^{2}$ Leandro Silva Medrano}

Arquiteto e Urbanista. Professor Livre-docente do Departamento de História da Arquitetura e Estética do Projeto da FAU-USP. Endereço postal: FAU Cidade Universitária, Rua do Lago 876, Cidade Universitária, São Paulo, SP, CEP 05.508-080 